\title{
A Clinical Study of Amoebic Dysentery and Its Homoeopathic Management
}

\author{
Dr. Siva Rami Reddy. E \\ BHMS, MD, PhD scholar \\ Sri Ganganagar Homoeopathic Medical College, Hospital and Research Center, \\ Sri Ganganagar, Rajasthan, India
}

\begin{abstract}
A Clinical Study of Amoebic Dysentery and Its Homoeopathic Management, Sri Ganganagar, Rajasthan, India.

Background: To study the clinical presentation of amoebic dysentery and to study the results of Homeopathic management and treatment of amoebic dysentery. To assess the influence of miasm in the case of Amoebic Dysentery.

Methodology: Thirty out-patients with clinically confirmed symptomatic cases of amoebic dysentery were entered trial and treated with Homoeopathic remedies on the basis of Homoeopathic principles with fixed criteria to know the results of treatment as recovered, improved or not improved. For the present study he patients who visited on Sriganganagar Homoeopathic Medical College, Hospital and Research Center, Sri Ganganagar, Rajsthan, India and peripheral Out Patient Department were selected on the inclusion and exclusion criteria.

Result: Totally 30 patients were selected for this study. At the end of the study it was observed that, out of 30 patients, 24 patients recovered (80\%), 5 case improved (16.66\%) andlcase is not improved (3.3\%). with the help of suitable homoeopathic medicines.

Conclusion: There were no side effects during the treatment and it can be concluded that Homoeopathic Medicines can be help the patient to take a new lease on life.

Keywords: Homoeopathic Medicines; Amoebic dysentery; Outcome.
\end{abstract}

\section{Introduction}

One of the first forms of this "Life" to develop was the lowly amoeba. Eons passed, and the amoeba evolved into different sprain one of them the Entamoeba histolytica, in the waters of the earth it waited, through millenniums, for the advent of man! Man evolved roomed the earth, drank its water \& sometimes developed amoebiasis, occasionally an amoebic liver abscess, ignorant of the cause, he statically suffered the disease caused by this microscopic predator until when the culprit was finally identified ${ }^{1}$.The clinical symptoms of amoebiasis caused by the protozoan parasites Entamoeba histolytica ranges from asymptomatic colonization to amoebic dysentery and invasive extra intestinal amoebiasis is most common in the form of liver abscess. Invasive amoebiasis is one of the world's most prevalent and fatal infectious diseases. Primarily it is a problem of the developing world; around 500 million people are infected worldwide while 75,000 die of the disease annually. Behind malaria and schistosomiasis it ranks third on the list of parasitic causes of death worldwide. E. histolytica and E. disparare currently recognized as distinct species, mostly based on genetic, biochemical, and immunological studies. It is therefore possible to obtain more reliable and correct epidemiological data using molecular, biochemical, and immunological features, and these allow better diagnosis and treatment.

The present study comprises systematic approach for evolving constitutional treatment for amoebic dysentery. Antibiotics particularly tetracycline, are useful as bacterial adjuvant. These drugs are not effective in ectopic infections for which chloroquine phosphate and nitridazol shows promise of efficiency. Metronidazol has become the preferred drug in treatment of amoebiasis. It is slow in toxicity and is effective against extra intestinal as well. However Metronidazol has been reported as being mutagenic in bacteria and carcinogenic in mice at doses much higher than those given for the treatment of amoebiasis. Finally its efficacy may not be as high, as originally reported ${ }^{2}$.

The history of amoebiasis perhaps is fairly typical the way in which most knowledge is gradually accumulated $^{3}$. Entamoeba histolytica is thought to infect $10 \%$ of world population and to produce more deaths than any other parasites. Although it has worldwide distribution infection rates are highest in warm climates and exceed 50\% in areas s where the level of sanitation is $10 w^{4}$. Amoebic liver abscess and colitis have become almost non- existent in Alaska \& Canada. In Canada amoebic injection is encountered only in small parts of India population among whom it is endemic ${ }^{5}$. In the tropics on account of heavy rainfall there is greater chance of the water supply being polluted from the washing of the sewage and hence the disease is more 
common in rainy season ${ }^{6}$. Amoebiasis may occur at any age, there is no sex or racial difference in the occurrence of the disease. Amoebiasis is frequently a house hold infection ${ }^{7}$, Invasive amoebiasis including amoebic lives abscess is much more common in males as compared to females ${ }^{8}$.According to K. Park: The term "amoebiasis" has been defined by W.H.O as: As the condition of harboring the protozoan parasite Entamoeba histolytica with or without clinical manifestations ${ }^{9}$. Clinical features are Pain or discomfort in liver area, at first dull \& aching or sensation of heaviness in right hypochondrium, later Sharp \& stabbing.

\section{Materials and Methodology}

Patients are considered on the basis of clinical presentations, i.e., pain in abdomen, loose motions mixed with blood \& mucus, fever. This study consists of 30 patients of amoebic dysentery, who attended OPD at Sri Ganganagar Homoeopathic Medical College and Hospital and its Peripheral O.P.D's. 30 cases were selected on the basis of inclusion and exclusion criteria.

Inclusion Criteria: Subjects of all ages, both sexes, different socio economic status and occupation in the background. Diagnosed cases of amoebic dysentery on basis of clinical presentation and lab investigations like-stool microscopic examination.

Exclusion Criteria: Chronic amoebic dysentery with its complications. Subjects suffering from terminal illness, those undergoing active treatment from other systems of medicine, surgical cases, those who are not able to communicate their symptoms. The outcomes were an improvement of symptoms recorded in monthly basis individual symptoms. A number of subgroup, Homoeopathic potency, age groups, and types of amoebic dysentery were analyzed

Statistical Analysis: Data were presented as proportion and percentage and difference in proportion were analyzed by using $\mathrm{T}$ test.

\section{Result}

Among 30 amoebic dysentery patients with mean \pm SD, maximum cases were observed in age group between $40-50$ years. And the minimum age incidence was found in 2 cases $(6.66 \%)$ in the age group between 50-60years. 8 cases $(26.66 \%)$ was found in age group between 10-20yrs, 7 cases $(23.33 \%)$ was observed in the age group between 30-40years. 3 cases (10\%) was observed in age group of 20- 30 yrs. the incidence was seen to be prominent in males with 22 cases $(73.33 \%)$ and females with 8 cases $(26.66 \%)$. In this study of 30 cases of amoebic dysentery, Pulsatilla Pratensis is more prescribed in 7 cases $(23.3 \%)$, each Mercurius solubilis, Mercurius corrosivus, Aloes socotrina and Calcarea carbonica are prescribed in each individual of 4 cases(13.33\%), Baryta carbonica, Nux.vomica are prescribed in 3cases in (10\%), Colchium Autumnale, Nat.muriaticum was prescribed in 2cases(6.67\%), Phosphorous, Lachesis, Dulcamara, Colocynth, Arsenicum album are least prescribed as a in each individual 1case (3.33\%). The study was done to show the results of 30 cases. Out of 30 cases maximum number of cases, i.e. 24 cases $(80 \%)$ recovered, 5 cases $(16 \%)$ improved and 1cases $(3.3 \%)$ showed no improvement

\section{Discussion}

The present study was carried on 30 cases that satisfied the criteria to study the role of Homoeopathic remedies in the treatment of Amoebic dysentery. Homoeopathy can be extremely effective in treating Amoebic dysentery which is one of the most common human gastro-intestinal problems. The infection is very common in developing countries like India. Various systems of medicines have faced difficulties in its management. Homoeopathic remedy prescribed on the basis of law of similar not only improved the Amoebic dysentery but also strengthened the body's immune system and to prevent future occurrences. During the study it was observed that highest incidence of Amoebic dysentery is seen in 10 cases of age group of 40-50 years (33.33\%), 8 cases in age group 10-20 years $(26.66 \%)$, 7 cases in age group of 30-40 years $(23.33 \%), 3$ cases in age group 20-30 years $(10 \%)$, \& least incidence is seen in 2 cases of age group 50-60 years (6.66\%), as adults will eat food outside so they prone to get infected easily.

There is no sex or racial difference in the occurrence of disease Infection can occur in both the sexes. As seen in the study 8 were females and 22 were males. Males were found more affected than the females. The male: female ratio was 1:3. In medical literature it is seen that, males have a slightly higher prevalence than females as it is found that males eat outside food more than females. So, they are more prone for faecal oral contamination. This study shows 22 cases (73.33) where males are affected and 8 cases (26.66) where females are affected. This study of the past also enables the physician to determine the constitutional and familial tendencies and the miasmatic influences that probably operate to the determent of the patient ${ }^{10 .}$ In the study of 30 cases of amoebic dysentery, Pulsatilla Pratensis was highly prescribed in 7 cases (23.3\%), Mercurius solubilis, Mercurius corrosivus, Aloes socotrina, Calcarea carbonica were prescribed in 4 cases $(13.33 \%)$, Baryta.carbonica, Nux vomica were prescribed in 3 cases (10\%), Colchium, Natrium muriaticum were prescribed in 2 cases $(6.67 \%)$, Arsenicum album, Colocynth, Dulcamara, Lachesis, Phosphorus were prescribed in 1 case $(3.3 \%)$ each. In 
the study conducted on 30 cases of Amoebic dysentery with Homeopathic remedies, it was found that 24 cases (80\%) were recovered, 5 cases (16\%) were Improved and 1 case (3.3\%) Not Improved.

\section{Conclusion}

The research shows that Homoeopathic medicine play an important role in the treatment of tonsillitis in paediatric age group. The study depicts that $73.33 \%$ of patients got relief from the Homoeopathy medicines and this is not a small number. Highest indicated remedy is Pulsatilla Pratensis, Mercurius solubilis, Mercurius Corrosivus., Aloes Socotrina, Calcarea carbonica, Of Nux vom., Baryta carbonica. (3 cases, 10\%), Natruium muriaticum., Colchicum each, Arsenicum album, Colocynthis, Dulcamera, Lachesis, Phosphorus each. Out of 30 cases, 24 cases have recovered 5 cases shows improvement and 1 cases not improved. Thus we can conclude that Homoeopathic medicines used with holistic approach are very effective in treating the cases of amoebic dysentery.

\section{Bibliography}

[1]. Kapoor. OP. Amoebic liver abscess. Bombay ( India); 1979,pg.no:15-17,21.

[2]. Schmidt. GD, Larey SR. Foundation pf parasitology, $4^{\text {th }}$ ed, united states of American, Times mirror, mostly college publishing; 1985pg.no: 95-105

[3]. Stllwell G.C. Amoebiasis its early historyNewyork; 1955 pg.no :606.

[4]. Rayan KJ,ET, AISherrries medical microbiology.US.pg.no: 661-663.

[5]. Kapoor.OP.Amoebic liver abscess. Bombay (india) 1979;pg.no:15,17,21.

[6]. Chatterjee KD; Human parasite diseases Calcutta .publication by author; 1952 pg.no61-71.

[7]. Park .K.Park's text book.PSM 14 ${ }^{\text {th }}$ edJabolpur M/S Banardidasbhandpublication; 1995.pg.no 167.

[8]. Dhawan VK. Amoebiosis 2(6).Dep of internal medicine kingl drew medicalCentre; CharlesRdrew university .UCLD 2001;june;pgno: $1 \& 16$.

[9]. Park. K. Text book of preventive \& social medicine. $23{ }^{\text {rd }}$ ed. Jabalpur: Banarsidas bhanot publishers; 2015 pg no: $241 \& 242$.

[10]. Dhawale ML. Principles \& practice of homoeopathy. 5th reprint ed. New Delhi: Indian Books \& Periodicals Publishers; 2010. p. 35, 50,65-6.

Figure 1. Age Incidence

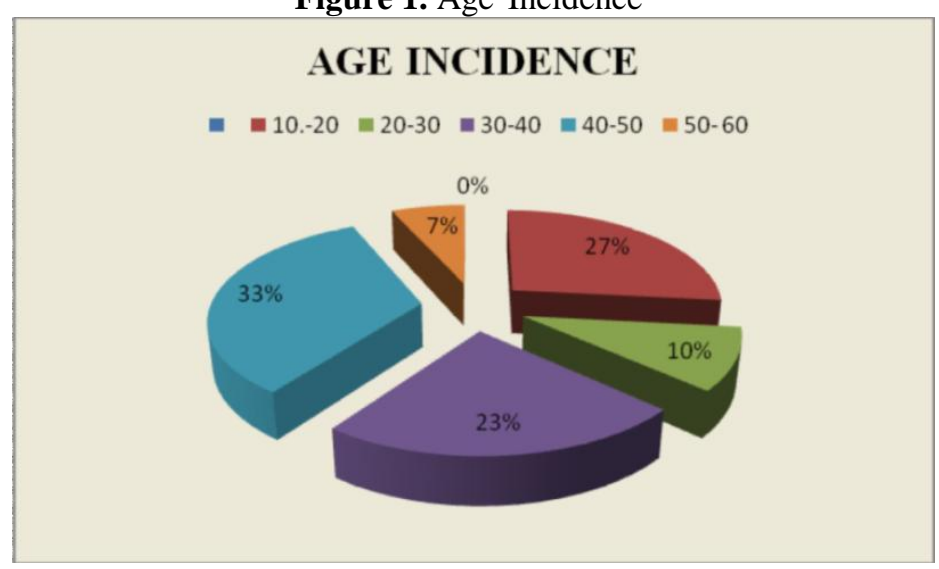

Figure 2. Sex Incidence

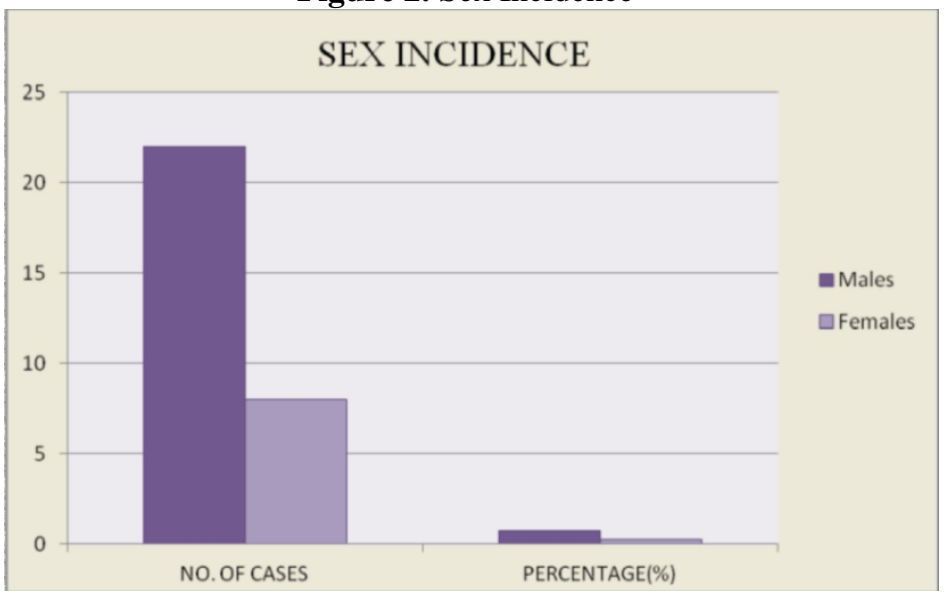

Figure 3. Indicated Remedies 


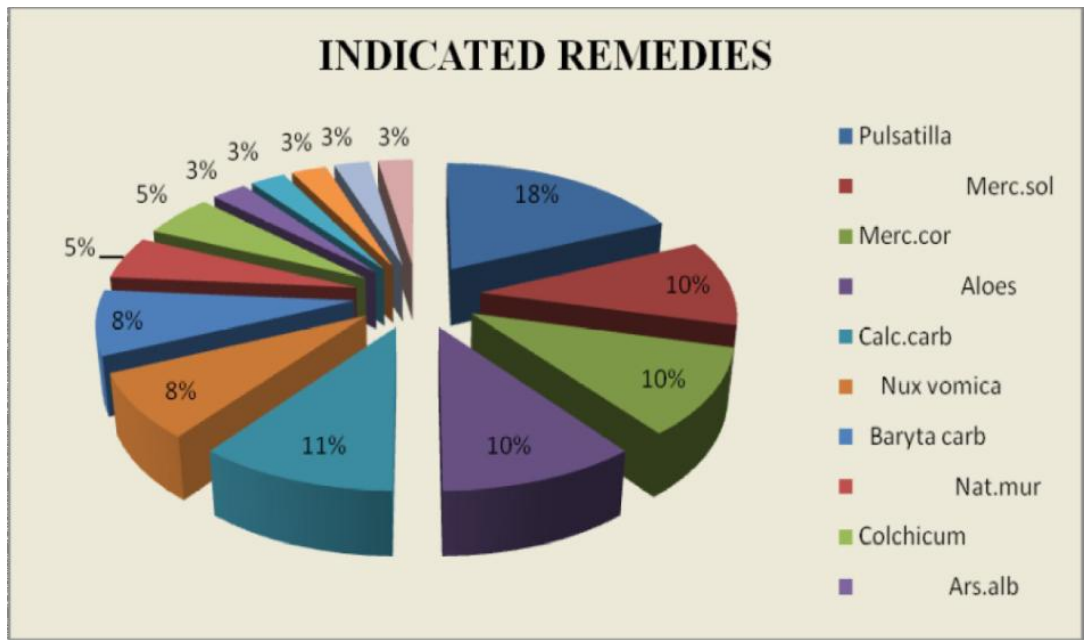

Figure 4. Results

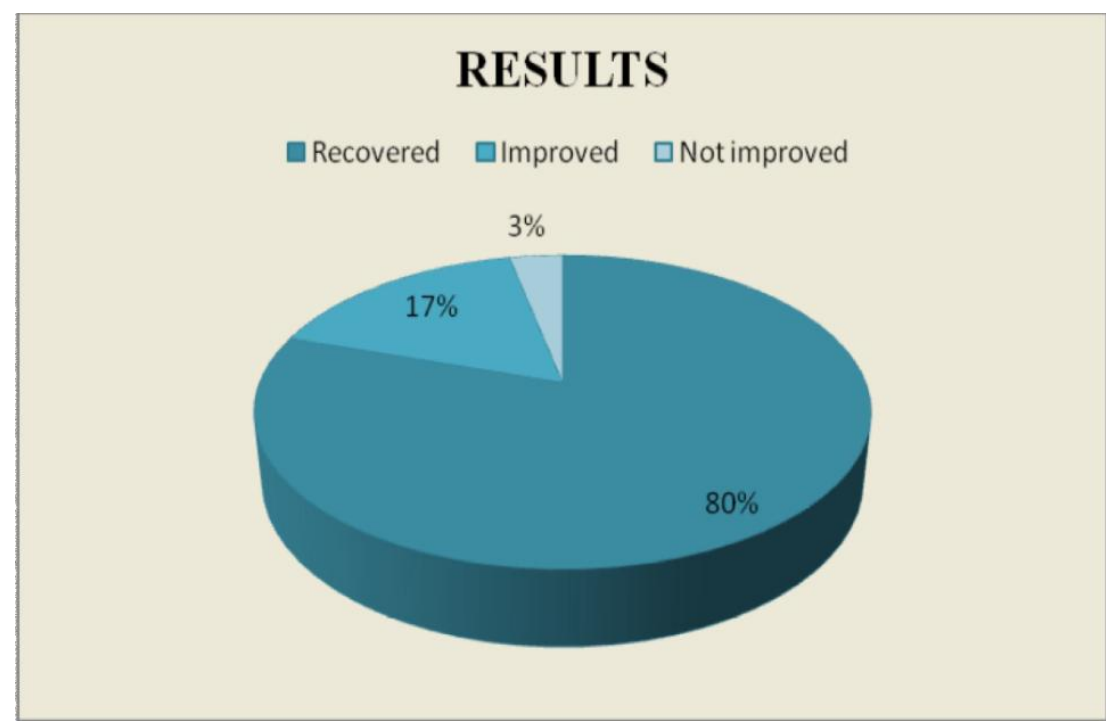

Table No. 1 Age Incidence

\begin{tabular}{|l|l|l|l|}
\hline Sl. NO. & AGE GROUP IN YEARS & NO. OF CASES & PERCENTAGE (\%) \\
\hline 1. & $10-20$ & 8 & $26.66 \%$ \\
\hline 2. & $20-30$ & 3 & $10 \%$ \\
\hline 3. & $30-40$ & 7 & $23.33 \%$ \\
\hline 4. & $40-50$ & 10 & $33.33 \%$ \\
\hline 5. & $50-60$ & 2 & $6.66 \%$ \\
\hline & Total & 30 & $100 \%$ \\
\hline
\end{tabular}

\begin{tabular}{|c|c|c|c|}
\hline S. NO. & SEX & NO. OF CASES & PERCENTAGE (\%) \\
\hline 1. & Males & 22 & $73.33 \%$ \\
\hline 2. & Females & 8 & $26.66 \%$ \\
\hline & Total & 30 & $100 \%$ \\
\hline
\end{tabular}

Table No. 3: Results

\begin{tabular}{|l|l|l|l|}
\hline S. NO. & RESULTS & NO. OF CASES & PERCENTAGE (\%) \\
\hline 1. & Recovered & 24 & $80 \%$ \\
\hline 2. & Improved & 5 & $16 \%$ \\
\hline 3. & Not improved & 1 & $3.3 \%$ \\
\hline & Total & 30 & $100 \%$ \\
\hline
\end{tabular}


Table No. 4: Indicated Remedies

\begin{tabular}{|l|l|l|l|}
\hline S.NO. & INDICATED REMEDIES & NO. OF CASES & PERCENTAGE (\%) \\
\hline 1. & Pulsatilla Pratensis & 7 & $23.3 \%$ \\
\hline 2. & Mercurius Solubilis & 4 & $13.33 \%$ \\
\hline 3. & Mercurius corrosives & 4 & $13.33 \%$ \\
\hline 4. & Aloes socotrina & 4 & $13.33 \%$ \\
\hline 5. & Calcarea Carbonica & 4 & $13.33 \%$ \\
\hline 6. & Nux vomica & 3 & $10 \%$ \\
\hline 7. & Baryta carbonica & 3 & $10 \%$ \\
\hline 8. & Natrium Muriaticum & 2 & $6.67 \%$ \\
\hline 9. & Colchicum & 2 & $6.67 \%$ \\
\hline 10. & Arsenicum Album & 1 & $3.33 \%$ \\
\hline 11. & Colcynthis & 1 & $3.33 \%$ \\
\hline 12. & Dulcamera & 1 & $3.33 \%$ \\
\hline 13. & Lachesis & 1 & $3.33 \%$ \\
\hline 14. & Phosphorous & 1 & $3.33 \%$ \\
\hline
\end{tabular}

